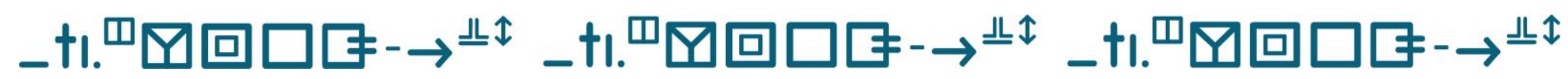

\section{Cotejo entre dois dicionários de Libras: análise dos microparadigmas}

\section{Appreciation between two Libras dictionaries: microparadigm analysis}

\author{
(iD) Leandro Andrade Fernandes
Universidade Federal de Uberlândia, Ituiutaba, Minas Gerais, Brasil \\ leandroandrade.letras@gmail.com \\ $\infty$ \\ Vanessa Regina Duarte Xavier \\ Universidade Federal de Catalão, Catalão, Goiás, Brasil \\ vrdxavier@gmail.com
}

Resumo: O dicionário é um instrumento presente em línguas que possuem um sistema de notação, de modo a representar a língua-alvo na modalidade escrita, e com o tempo passam a ser instrumentos normatizadores. Para a elaboração de um verbete, o lexicógrafo necessita estabelecer critérios, selecionando elementos que sejam úteis para seus consulentes. Desta forma, intentamos realizar a avaliação de dois dicionários de Língua Brasileira de Sinais (Libras), sendo eles o "Dicionário llustrado de Libras" (2011) e o "Dicionário Novo DEIT-Libras: Língua de Sinais Brasileira" (2013), concernindo estes os mais representativos da supracitada língua. À vista disso, verificamos a utilização dos microparadigmas nos verbetes, consoantes às informações presentes em textos externos, de forma a apresentar informações linguísticas que auxiliem o consulente no momento de consulta às obras. Propomos, assim, um cotejo entre os dicionários referidos em termos de sua estrutura. 
Palavras-chave: Dicionários. Libras. Microparadigmas.

Abstract: The dictionary is an instrument present in languages that have a notation system, in order to represent the target language in written form, and over time they become standardizing instruments. For the elaboration of an entry, the lexicographer needs to establish criteria, selecting elements that are useful for their consultants. Thus, we intend to carry out the evaluation of two Libras dictionaries, which are the "Dicionário llustrado de Libras" (2011) and the "Dicionário Novo DEIT-Libras: Língua Brasileira de Sinais" (2013), these being the most representative of the aforementioned language. Thus, we will verify the use of microparadigms in the entries, depending on the information present in external texts, in order to present linguistic information to assist the consultant when consulting works. Therefore we propose a comparison between the dictionaries referred in terms of their structure.

Keywords: Dictionaries. Libras. Microparadigms.

Submetido em 29 de abril de 2021.

Aceito em 04 de junho de 2021.

Publicado em 25 de novembro de 2021. 


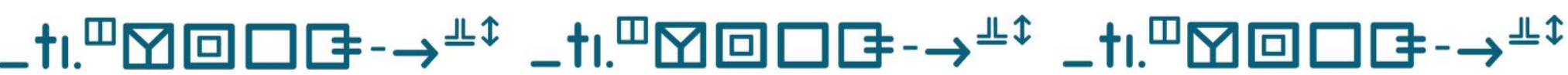

Cotejo entre dois dicionários de Libras: análise de microparadigmas

Leandro Andrade Fernandes • Vanessa Regina Duarte Xavier

\section{Introdução}

O presente trabalho é um recorte da dissertação intitulada "bases linguísticas e lexicográficas para a construção de um Glossário bilíngue em Libras-ELiS/português e português/Libras - ELiS", defendida no âmbito do programa de Pós-Graduação em Estudos da Linguagem, da Universidade Federal de Goiás-Regional Catalão. Aqui, tencionamos evidenciar o cotejo realizado entre dois dicionários de Libras, sendo eles: "Dicionário llustrado de Libras" - DIL, de Brandão (2011) e o "Novo DEIT-Libras: Língua Brasileira de Sinais" - DEIT, de Capovilla, Raphael e Maurício (2013).

O dicionário é um instrumento presente em línguas que possuem um sistema de notação, de modo a representar a língua-alvo na modalidade escrita, e com o tempo passam a ser instrumentos normatizadores. Assim, ter um registro do léxico de um sistema linguístico qualquer é importante para a sociedade e para a língua, uma vez que:

[...] o dicionário de língua consiste na única obra que sistematiza e legitima o léxico de um idioma, funcionando como uma espécie de cartório de palavras, e ainda como instrumento de autoridade que fixa padrões linguísticos. E, como tal, assume papel de um código normativo que define um paradigma modelar dos usos e sentidos das palavras e expressões de um idioma (KRIEGER, 2011, p. 134).

Existem diferentes tipos de dicionários, como infantis, escolares, padrão, os thesauri, dentre outros. Importa observar que cada dicionário é elaborado levando em consideração o público-alvo, assim, os seus elementos constitutivos variam entre si. O lexicógrafo, profissional que tem como objetivo a elaboração de dicionários, "como linguista, poderá escolher uma técnica descritiva embasada, por exemplo, numa teoria gramatical que Ihe permita construir modelos capazes de dar conta da estruturação adequada dos verbetes de seu 


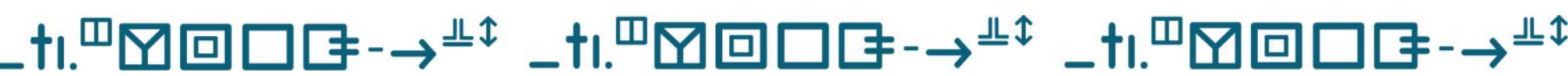

Cotejo entre dois dicionários de Libras: análise de microparadigmas Leandro Andrade Fernandes • Vanessa Regina Duarte Xavier

dicionário", conforme pontua Borba (2011, p. 18). Para estabelecer a estrutura da obra e de seus verbetes, necessita-se da elaboração de critérios acerca dos elementos que devem estar presentes na macro e microestrutura ${ }^{1}$.

Assim, ao explorar diferentes dicionários, é possível perceber uma heterogeneidade em relação às informações presentes nos verbetes. Dentre tais informações, podemos destacar: etimologia, exemplo, classe gramatical, sinônimos, entre outros. No tocante aos dicionários de línguas de sinais - LS, notam-se algumas distinções em relação à presença ou ausência de alguns microparadigmas², como apontam Fernandes e Xavier (2019).

Por essa razão, intentamos aqui realizar a avaliação dos elementos presentes em verbetes do DIL e do DEIT, a fim de observar os critérios usados ao longo das obras e a coerência no seu uso. Além disso, apresentamos um breve retrospecto ao que se refere às obras lexicográficas voltadas para a Língua Brasileira de Sinais (Libras), de modo a enfatizar o desenvolvimento diacrônico destas obras, que serão elucidadas em breves análises metalexicográficas. Este estudo metalexicográfico, concernente às obras de referências em Libras, tem como objetivo demonstrar as diferentes estruturas presentes nos dicionários, desde a primeira obra ascendendo aos dias atuais.

Como estratégia metodológica, selecionamos as duas obras dicionarísticas mais conhecidas, utilizadas e que possuem maior representação do léxico da Libras. Como base para as análises, recorremos a autores como

\footnotetext{
${ }^{1}$ Rey-Debove (1971, p. 21) define macroestrutura como "o conjunto das estradas", assim, entendemos que este termo se refere ao arranjo das entradas, a organização da estrutura dos verbetes, assim como das informações presentes no mesmo. E ao termo microestrutura o supracitado autor define-o como "o conjunto das informações ordenadas de cada verbete após a entrada", portanto, concerne na organização dos microparadigmas presentes nos verbetes.

${ }^{2} \mathrm{O}$ termo microparadigma, conforme apresenta Andrade (1998), refere-se às informações concernentes à uma entrada, variáveis em quantidade e qualidade, de acordo com o objetivo do instrumento lexicográfico, ou seja, o termo alude às múltiplas informações referentes ao lema-entrada.
} 


\section{_t..}

Cotejo entre dois dicionários de Libras: análise de microparadigmas

Leandro Andrade Fernandes • Vanessa Regina Duarte Xavier

Stein (1991), Murakawa (2011) e Zavaglia (2011), dentre outros, que nos possibilitaram realizar um cotejo metalexicográfico destas obras.

Pretendemos, assim, que este trabalho possa contribuir de forma significativa com trabalhos futuros que visem à construção de dicionários e/ou glossários em Libras, bem como com os consulentes, ao denotarmos a estrutura destas obras, assim como o rigor e/ou a falta dele no tratamento das informações.

\section{Um passeio pelos estudos lexicográficos da Libras}

O primeiro trabalho que objetivou a organização de um repertório lexical da Libras de que se tem notícia é o de Flausino José da Costa Gama (1875), intitulado "A Iconographia dos Signaes dos Surdos-Mudos". Entretanto, Sofiato (2005) argumenta que o trabalho é, na verdade, uma reprodução da obra de Pélissier (1856), pois apresenta a mesma quantidade de sinais e semelhanças na indexação semântica. Tobias Leite, no prefácio presente na obra de Gama (1875, p. 2), afirma que "Os pais, os professores primários, e todos os que se interessarem por esses infelizes, ficarão habilitados para os entender e se fazerem entender". O juízo de valor compartilhado pela sociedade naquele momento é claramente inferido na citação anterior, em que os surdos eram classificados como doentes, em uma visão patológica, percebidos como incapazes e muitas vezes socialmente excluídos. Esta óptica não é mais compartilhada por pesquisadores, uma vez que, a partir de estudos, provou-se a maestria do sujeito surdo não apenas no processo de ensino e aprendizagem, mas como cidadão ativo e produtivo na sociedade.

Desta maneira, podemos entender que a obra de Gama (1875) é essencialmente didática e não possui como objetivo principal o registro amplo do léxico da língua, mas sim a criação de um material para pessoas ouvintes, 


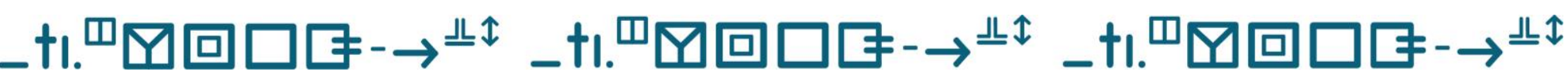

Cotejo entre dois dicionários de Libras: análise de microparadigmas Leandro Andrade Fernandes • Vanessa Regina Duarte Xavier

que se interessassem por aprender a Libras. O citado trabalho é organizado em ordem onomasiológica, que, conforme Gonçalves (2013, p. 54), “não toma como base conceitos individuais e, sim, as relações de sentido existentes entre as palavras", apresentando, neste caso, os seguintes grupos semânticos: alimentos, objetos de mesa; bebidas e objetos de mesa; objetos para escrever; objetos de aula; individualidade e profissão; pássaros, peixes e insetos; adjetivos; adjetivos (qualidades morais); pronomes e os três tempos absolutos do indicativo; verbos; advérbios; preposições e conjunções. A seguir, demonstramos uma pequena parte do trabalho do autor:

Figura 1: Objetos para escrever.

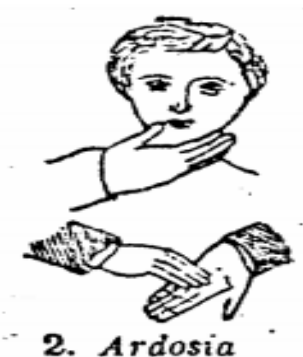

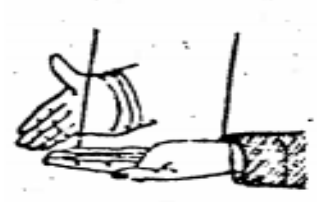

3. Caderno

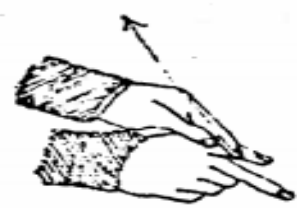

4. Penina

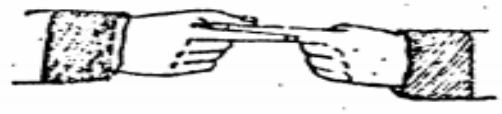

5. Lapis de pedra

Fonte: Gama (1875, p. 8).

Descrição da imagem: figura ilustrativa, recolhida da obra de Gama (1875) com o objetivo de demonstrar aos leitores a proposta lexicográfica do autor. Apresenta os verbetes "ardosia, caderno, penna e Lapis de pedra".

Assim, além da tabela do alfabeto manual, a obra contém o total de trezentos e quarenta e dois (342) sinais distribuídos entre as quinze (15) categorias apresentadas anteriormente. Sua organização onomasiológica apresenta, inicialmente, como pode ser observado na figura anterior, a ilustração referente ao léxico na Libras e seu equivalente na língua portuguesa - LP. Após cada categoria, há uma descrição da realização dos sinais ali presentes, de forma a serem identificados pelo número que antecede 0 equivalente em LP, conforme ilustra a figura a seguir: 


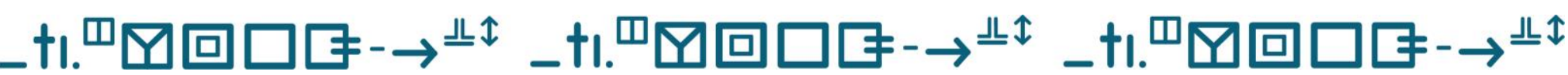

Cotejo entre dois dicionários de Libras: análise de microparadigmas Leandro Andrade Fernandes • Vanessa Regina Duarte Xavier

Figura 2: Descrição dos objetos "ardósia" e "caderno", respectivamente.

Nig. 2.-Humedecer com o halito a palma da mão esquerda, e fazer signal de a limpar com a mão direita.

Fig. 3.-Fingir que tem um caderno sob o braço-esquerdo,-e mostrar com o bordo interno da mão direita as extrenidades do caderno, os seus lados superiores e inferiores.

Fonte: Gama (1875, p. 9).

Descrição da imagem: figura ilustrativa, recolhida da obra de Gama (1875) para elucidar a forma de descrição dos sinais "ardosia e caderno" presentes na obra do supracitado autor.

A obra de Gama, apesar de não ser essencialmente lexicográfica, muito contribuiu para os estudos posteriores, pois nela é possível identificar elementos que ainda hoje estão presentes em dicionários de Libras, como o uso da ilustração para o referente na Libras e a descrição detalhada da realização do sinal.

Em 1969, o padre Eugênio Oates publicou o livro intitulado “Linguagem das mãos", em ordem onomasiológica, com mil duzentos e cinquenta e oito (1.258) sinais organizados nas seguintes categorias: verbos; substantivos, adjetivos e advérbios; preposições, pronomes e conjunções; cores; homem e família; alimentos e bebidas; animais; o mundo e a natureza; religião; tempo; regiões do mundo e alguns países; estados brasileiros, territórios federais e capitais; vestuários e acessórios; esportes e jogos recreativos; antônimos e números cardinais. O supracitado trabalho apresenta a seguinte estrutura: registro do sinal utilizando uma imagem, o equivalente em português e a descrição detalhada da realização do sinal. É possível perceber o mesmo padrão estrutural entre Gama (1975) e Oates (1969), diferenciando-se em sua organização categorial e pela quantidade de entradas.

Atualmente, podemos destacar alguns trabalhos lexicográficos voltados para a Libras, dentre estes a coleção de Honora e Frizanco (2009, 2010, 2011), designada de "Livro llustrado de Língua Brasileira de Sinais". Dividida em três 


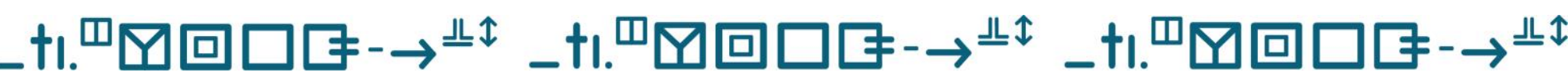

Cotejo entre dois dicionários de Libras: análise de microparadigmas Leandro Andrade Fernandes • Vanessa Regina Duarte Xavier

volumes, está organizada em ordem onomasiológica e, apesar de não possuir em seu título o termo dicionário, pode ser entendida como tal, por ser esta uma obra que visou à compilação do léxico da Libras. Há, no corpo da obra, textos explicativos voltados para a história da educação de surdos, o surdo na idade moderna, breve panorama das leis em vigência no Brasil, aspectos gramaticais da Libras, variação linguística, iconicidade, arbitrariedade, entre outros.

Após a apresentação dos textos externos ${ }^{3}$, é possível encontrar uma lista de palavras/sinais, arrolada por grupos semânticos e dentro de cada grupo foi utilizada a ordem alfabética da LP. Apesar disso, entendemos que a ilustração se refere à cabeça do verbete, pois é anterior ao lexema em LP, mesmo que a nomenclatura esteja em ordem alfabética pelos lexemas em LP. Os três volumes acomodam o total de cem grupos semânticos, por exemplo: verbos, religião, profissão, informática, morte, verduras, calçados, documentos, casa, escola e outros. É importante destacar que nos textos externos não há indicações precisas sobre a coleta do corpus.

Novamente, é perceptível a semelhança na estrutura desta obra ao compará-la à de Gama (1875), por apresentar a ilustração do sinal, o equivalente em LP e uma descrição detalhada do sinal, respectivamente. No trabalho de Honora e Frizanco (2009, 2010, 2011), a descrição do sinal é organizada a partir dos parâmetros ${ }^{4}$ da Libras, proporcionando ao consulente a compreensão em nível morfológico do signo linguístico em Libras. Além disso, utiliza a ilustração como auxílio na compreensão do verbete, elemento ausente nas duas obras de teor lexicográfico apresentadas anteriormente, e usufrui de

\footnotetext{
${ }^{3}$ Neste trabalho, textos informativos precedentes ou posteriores aos verbetes, são denominados de "textos externos", termo presente em Welker (2004, p. 78), referente a elementos como prefácio, introdução, certas curiosidades, entre outros.

${ }^{4}$ De acordo com Carvalho (2021, p. 39), "Os parâmetros da Libras são um grupo de ações realizadas com uma mão ou com as duas mãos para formar uma palavra", ou seja, são unidades mínimas que isoladamente não possuem significado.
} 


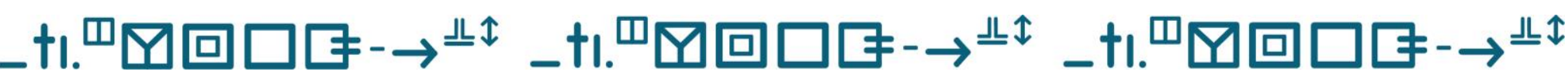

Cotejo entre dois dicionários de Libras: análise de microparadigmas Leandro Andrade Fernandes • Vanessa Regina Duarte Xavier

uma organização mista, por ser onomasiológico e dentro de cada categoria possuir uma organização semasiológica ${ }^{5}$ da LP, ou seja, em ordem alfabética. Há outros trabalhos lexicográficos em formato digital, como o "Acessibilidade Brasil"w, organizado por diferentes especialistas, dentre eles professores, engenheiros, arquitetos, jornalistas, e outros, e o "Glossário Libras"7, da Universidade Federal de Santa Catarina. Além disso, há trabalhos voltados para áreas específicas na Libras, conhecidos como dicionários ou glossários especializados ou terminológicos. Dentre as pesquisas de mestrado e doutorado, é possível perceber a utilização recorrente dos termos bilíngue ou Libras-português, justificável pela Libras e a LP compartilharem o mesmo território. Além disso, estas obras vão ao encontro da política bilíngue, visando à educação de surdos na modalidade sinalizada, com a Libras, e na modalidade escrita, com a LP.

\section{Caminhos metodológicos}

Como estratégia metodológica, selecionamos dois dicionários de Libras para análise, sendo estes os mais representativos desta língua, a saber, “O Dicionário llustrado de Libras” - DIL e o “Dicionário Novo DEIT-Libras: Língua de Sinais Brasileira" - DEIT. O DIL foi criado pela professora Flavia Brandão8, formada em Artes Plásticas pela Fundação Armando Álvares Penteado (FAAP). Lançando em 2002 seu primeiro dicionário de Libras em CD-ROM, em 2011

\footnotetext{
${ }^{5}$ Baldinger (1970, p. 115) aponta que "A semasiologia parte de uma forma (significante) para chegar a uma série de objetos mentais diferentes, mas também é possível escolher 0 caminho oposto: partir de um objeto mental para examinar todas as formas e significantes (designações) que os realizam."

${ }^{6} \mathrm{O}$ glossário pode ser acessado no endereço: <www.acessibilidadebrasil.org.br/libras/>.

${ }^{7} \mathrm{O}$ glossário pode ser acessado no endereço: < http://www.glossario.libras.ufsc.br/letraslibras>.

${ }^{8}$ Flavia Brandão nasceu em 1965 na cidade de São Paulo, aos nove anos contraiu caxumba, e devido a complicações perdeu a audição do ouvido esquerdo.
} 


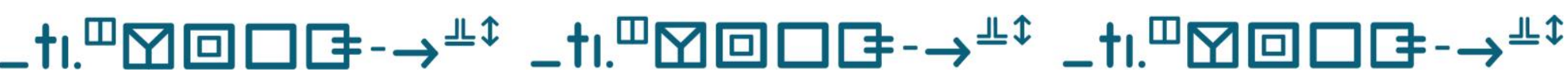

Cotejo entre dois dicionários de Libras: análise de microparadigmas Leandro Andrade Fernandes • Vanessa Regina Duarte Xavier

publica o dicionário impresso aqui analisado. Ela recebeu prêmios importantes com sua primeira publicação: o Certificado de Tecnologia Social Efetiva, pela Fundação Banco do Brasil, pela Unesco e pela Comunicação Institucional da Petrobras, por meio do prêmio Fundação Banco do Brasil de Tecnologia Social (edição 2005).

Figura 3: Capa do dicionário llustrado de Libras.

Fonte: página da Editora Global99.

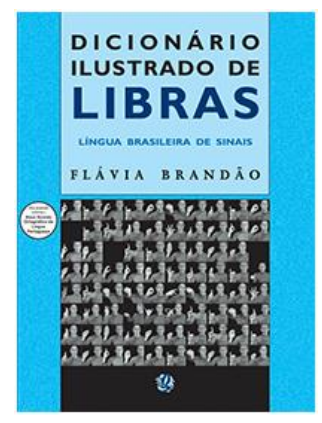

Descrição da imagem: imagem ilustrativa da capa do dicionário de Brandão (2011).

Podemos destacar que o DIL é composto por três mil duzentos e doze (3.212) sinais e, conforme aponta Brandão (2011, p. 9), "pode ser consultado por todos os públicos". Este dicionário pode ser classificado como bilíngue, embora este termo não seja encontrado na apresentação da obra, pois reúne lexemas gerais do léxico da Libras, a fim de orientar os consulentes no sentido das lexias da LP para a Libras. Em textos externos, há informações que auxiliam o consulente durante o manuseio da obra, tais como: Libras - Língua Brasileira de Sinais; Dicionário Ilustrado de Libras; como usar; exemplos de: configurações de mão, posicionamento e outras orientações e bibliografia. É interessante observar que os textos são curtos, facilitando a sua leitura. No entanto, não encontramos na obra indicações de como o corpus presente no dicionário foi

\footnotetext{
${ }^{9}$ Disponível em: <http://globaleditora.com.br/?s=dicion\%C3\%A1rio+ilustrado+de+libras>. Acesso em: dez. de 2017.
} 


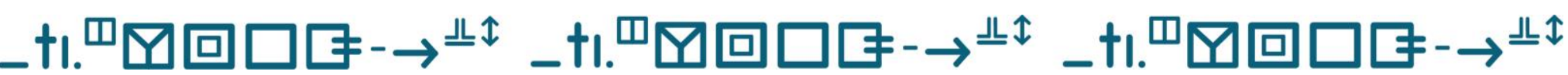

Cotejo entre dois dicionários de Libras: análise de microparadigmas Leandro Andrade Fernandes • Vanessa Regina Duarte Xavier

coletado, informação importante para se observar a sua representatividade do léxico da língua utilizado em diversas situações de uso.

Por sua vez, o DEIT consiste na terceira edição do dicionário de Libras conhecido como Capovilla. Este foi organizado por Fernando César Capovilla, Walkiria Duarte Raphael e Aline Cristina L. Mauricio. Conforme os autores (2013, p. 45), a obra é baseada em Linguística e Neurociência Cognitiva e em pesquisas em Lexicografia da Libras e cognição de surdos, que tiveram início em 1989 no "Laboratório de Neuropsicolinguística Experimental", abrigado na Universidade de São Paulo - USP. No corpo do dicionário, dividido em dois volumes, é possível encontrar o total de dez mil duzentas e noventa e seis (10.296) entradas, somando as variações e as duplicações de um mesmo termo - ponto este que será discutido na próxima seção.

Figura 4: Capa do dicionário Novo DEIT-Libras: língua de sinais brasileira.

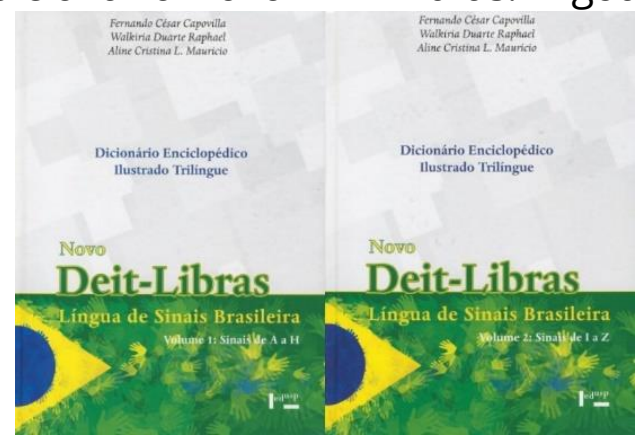

Fonte: Página da USP ${ }^{10}$.

Descrição da imagem: imagem ilustrativa da capa do dicionário de Capovilla, Raphaele Mauricio (2013).

Em textos externos, podemos encontrar uma vasta quantidade de informações, por exemplo: como usar esta $3^{a}$ edição revista e ampliada do Novo DEIT-Libras; uma descrição dos paradigmas neuropsicolinguísticos para refundação conceitual e metodológica da linguagem falada, escrita e de sinais

\footnotetext{
${ }^{10}$ Disponível em: <http://www.ip.usp.br/laboratorios/lance/Livros/capas/>. Acesso em: dez. de 2017.
} 


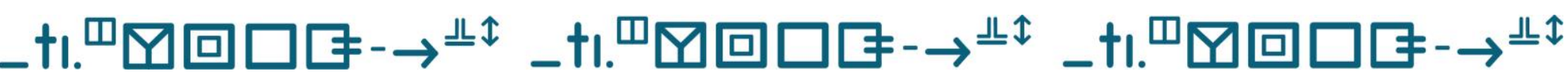

Cotejo entre dois dicionários de Libras: análise de microparadigmas Leandro Andrade Fernandes • Vanessa Regina Duarte Xavier

para a alfabetização de ouvintes, deficientes auditivo, surdos e surdocegos; Alfabeto manual de Libras, e Formas de mão usadas em Libras, entre outras. Com a apresentação das obras selecionadas, passemos agora para a apresentação e análise dos dados.

\section{Análise dos dados}

Os dados obtidos com o preenchimento do instrumento foram tabulados e serão apresentados a seguir.

De modo a orientar os leitores, apresentaremos as análises separadamente. Inicialmente os dados obtidos na avaliação do DIL e posteriormente os do DEIT. Assim, em relação à macroestrutura do DIL, podemos apontar a organização semasiológica dos verbetes, em ordem alfabética da LP, assim como a entrada em caixa alta e em negrito, além do rigor lexicográfico. Em apêndices do dicionário, há algumas informações, organizadas por grupos semânticos, sendo elas: alfabeto, números, dias da semana, meses do ano e expressões de gentileza e cumprimentos. Além disso, as supracitadas categorias também podem ser encontradas no corpo do dicionário. Por conseguinte, apresentamos a seguir a estrutura-base dos verbetes encontrados no DIL:

Quadro 1: Estrutura base dos verbetes do DIL, de Brandão (2011).

\begin{tabular}{|l|l|}
\hline \multicolumn{1}{|c|}{ Microparadigmas } & \multicolumn{1}{c|}{ Definição } \\
\hline Sinal & $\begin{array}{l}\text { "É o gesto ou o movimento que representa uma ou mais palavras } \\
\text { em português". }\end{array}$ \\
\hline Setas & $\begin{array}{l}\text { "Presentes em alguns sinais, indicando a direção, o sentido e a } \\
\text { extensão do movimento da(s) mão(s)". }\end{array}$ \\
\hline Sequência fotográfica & "Mostra o percurso das mãos ao executar o sinal". \\
\hline Asterisco & $\begin{array}{l}\text { "Indica que a palavra entrada também aparece no rodapé, } \\
\text { remetendo para outro sinal". }\end{array}$ \\
\hline $\begin{array}{l}\text { Entrada e descrição } \\
\text { do movimento }\end{array}$ & $\begin{array}{l}\text { "Palavra a consultar e explicações de como o sinal deve ser } \\
\text { executado, incluindo a configuração e o posicionamento da(s) }\end{array}$ \\
\hline
\end{tabular}




\section{_tı.}

Cotejo entre dois dicionários de Libras: análise de microparadigmas Leandro Andrade Fernandes • Vanessa Regina Duarte Xavier

\begin{tabular}{|l|l|}
\hline & $\begin{array}{l}\text { mão(s), direção, sentido, velocidade do movimento, quantidade de } \\
\text { repetição, expressão fácil etc". }\end{array}$ \\
\hline Ilustração & $\begin{array}{l}\text { "Presente na maior parte dos verbetes, representa o significado do } \\
\text { sinal". }\end{array}$ \\
\hline Significado & $\begin{array}{l}\text { "Explica o significado da palavra, suas possíveis variações e } \\
\text { sinônimos". }\end{array}$ \\
\hline Sinal igual & $\begin{array}{l}\text { "Indica outras palavras que podem ser representadas com este } \\
\text { mesmo sinal". }\end{array}$ \\
\hline Palavra no rodapé & $\begin{array}{l}\text { "Cada palavra indica o verbete que deve ser consultado (cuja } \\
\text { entrada é sinônimo ou tem significado análogo), remetendo para o } \\
\text { sinal a ser executado". }\end{array}$ \\
\hline
\end{tabular}

Fonte: Elaborado pelos autores, com base em Brandão (2011, p. 10-11).

Descrição da imagem: quadro explicativo, elaborado pelos autores, com os nove microparadigmas e suas definições presentes em verbetes do dicionário de Brandão (2011).

É interessante observar que, no microparadigma entrada e descrição do movimento, a autora não leva em consideração os parâmetros Orientação da Palma (OP) e Ponto de Articulação (PA), sendo estes, dois dos cinco parâmetros da estrutura morfológica da Libras. Selecionamos um verbete para elucidar as informações apresentadas no quadro anterior:

Figura 5: Verbete "acordar".
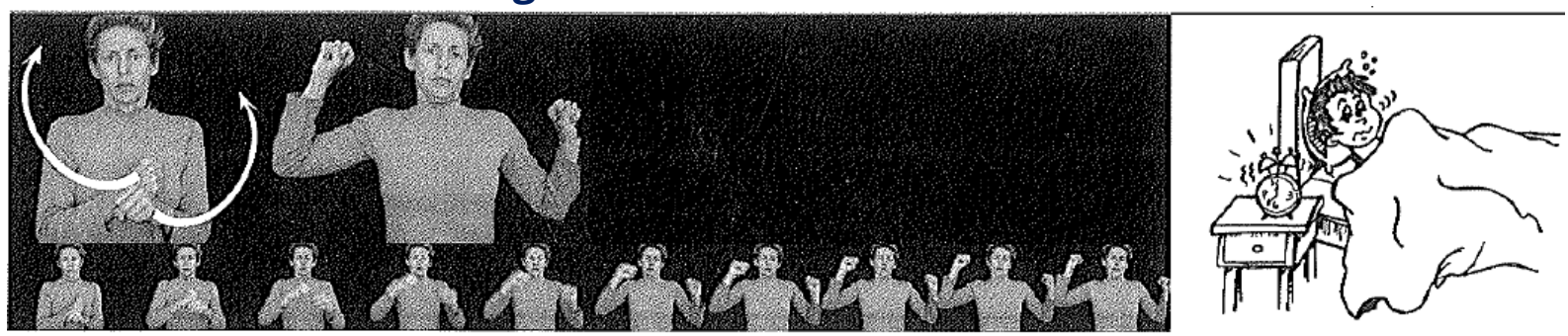

ACORDAR * -- Mãos fechadas em "S" se cruzando pe'os punhos (itoto 1). Movè-las simutanearnente para cima e para as laterais, imitando o gesto da quem està se espreguiçando. - Acordar: Sär do sono ou da sono:encia. Sinal igual: DESPERTAR

Fonte: Brandão (2011, p. 29).

Descrição da imagem: figura ilustrativa do verbete "acordar" em Brandão (2011), proporcionando aos leitores deste trabalho a possibilidade de compreender melhor a análise realizada.

$\mathrm{Na}$ figura acima, podemos visualizar todos os microparadigmas elencados e descritos por Brandão (2011). Importante destacar o rigor estrutural desta obra, pois as informações presentes em textos externos constam de fato nos verbetes. O primeiro elemento que pode ser visualizado 


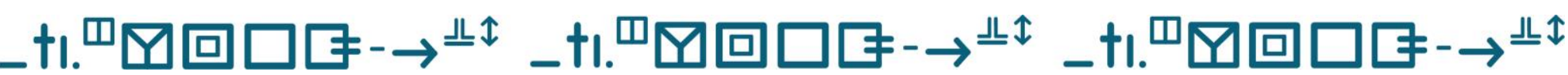

Cotejo entre dois dicionários de Libras: análise de microparadigmas Leandro Andrade Fernandes • Vanessa Regina Duarte Xavier

na figura acima, em ordem linear, ou seja, da esquerda para a direita, é o sinal em imagem que, em dicionários de línguas orais, é representado pela grafia do termo em sua forma canônica, na categoria conhecida como entrada.

Neste dicionário, apesar de o sinal em imagem ser o primeiro elemento, ou seja, a cabeça do verbete, não possui a denominação de entrada. Em sequência, após o sinal, há a sequência fotográfica e a ilustração, em que percebemos o item entrada incorporado à descrição do movimento que forma o significante do termo em Libras. Entendemos que, por não haver uma escrita oficial para a Libras, Brandão (2011) utiliza como recurso para a representação de suas unidades linguísticas imagens, fotos e ilustrações; por este motivo, o sinal no DIL pode ser considerado o equivalente na língua-alvo.

A autora acrescenta o item sinal igual, representando os sinônimos na LP. Como exemplo, destacamos o verbete "laranja" (fruta), para o qual Brandão (2011, p. 399) apresenta como sinal igual ao lexema "lima". Observa-se que os homônimos não foram alocados em um mesmo verbete, visto que a unidade linguística "sábado", que é representada pelo mesmo sinal, (laranja) na Libras, não está presente no item sinal igual, mas sim em uma entrada independente, conforme se pode observar na imagem a seguir:

Figura 6: Verbete "laranja".
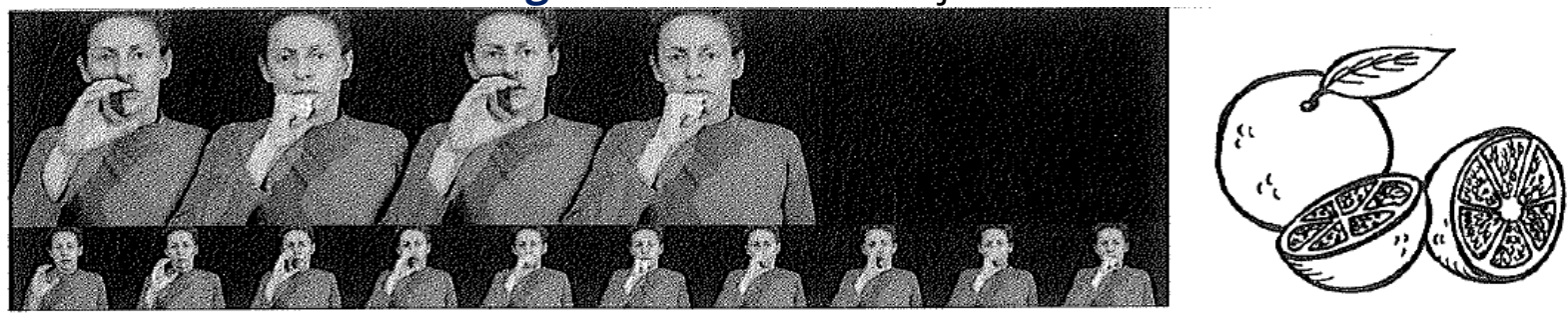

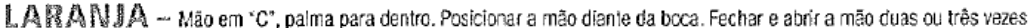

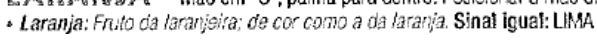

Fonte: Brandão (2011, p. 399) ${ }^{11}$.

\footnotetext{
${ }^{11}$ Texto definitório do verbete "laranja"(BRANDÃO, 2011, p. 538): "Fruto da laranjeira: de cor como a da laranja".
} 


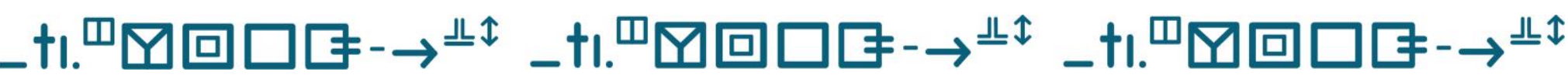

Cotejo entre dois dicionários de Libras: análise de microparadigmas Leandro Andrade Fernandes • Vanessa Regina Duarte Xavier

Descrição da imagem: figura ilustrativa do verbete "laranja" em Brandão (2011), proporcionando aos leitores deste trabalho a possibilidade de compreender melhor a análise realizada.

Esta organização é discutida entre lexicógrafos, como apontado por Murakawa e Zavaglia (2011, p. 39-41), que abordam a dificuldade para a distinção entre as formas homônimas e polissêmicas e sua organização em dicionários. Pode-se observar na entrada "ponto" (BRANDÃO, 2011, p. 538), que há apenas a acepção pertencente à gramática de "sinal usado para finalizar frases ou abreviar palavras". Algumas de suas lexias compostas possuem entradas próprias, como "ponto cirúrgico" e "ponto de ônibus"; enquanto outras lexias compostas estão ausentes, como: "linha de costura", "linha telefônica", "linha de ônibus", e outras.

Outro elemento a ser discutido são as palavras no rodapé, que evidenciam lexemas da LP que possuem o mesmo equivalente em Libras. Diante disso, ao analisarmos a entrada "alienação", percebe-se que este nos remete aos verbetes "doido" e "louco". Conforme Brandão (2011), as três unidades linguísticas são representadas pelo mesmo sinal.

A ilustração, item importante em dicionários infantis e pouco utilizado em dicionários para adultos, é um recurso válido no auxílio da compreensão do significado, especialmente em relação à Libras. Mas, nos dicionários de Libras, há uma ilustração para cada entrada, além de uma seleção de imagens de forma randômica, ocasionando a não representação fidedigna do verbete. Desta forma, os sinais de verbos, adjetivos e substantivos podem não apresentar uma ilustração precisa, consoante à entrada, devido à distinção de toda uma gama de conceitos expressos pela unidade linguística em relação à ilustração. Como exemplo, podemos citar as entradas "prazer", "negligente" e "natural", que podem proporcionar ao consulente uma significação errônea ou insatisfatória: 


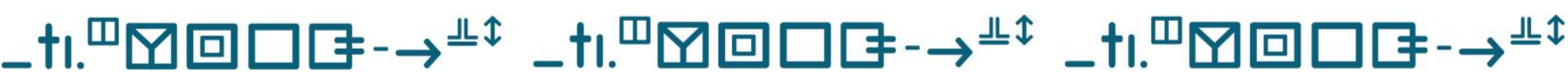

Cotejo entre dois dicionários de Libras: análise de microparadigmas Leandro Andrade Fernandes • Vanessa Regina Duarte Xavier

Figura 7: Ilustrações dos verbetes "prazer", "negligente" e "natural", respectivamente.
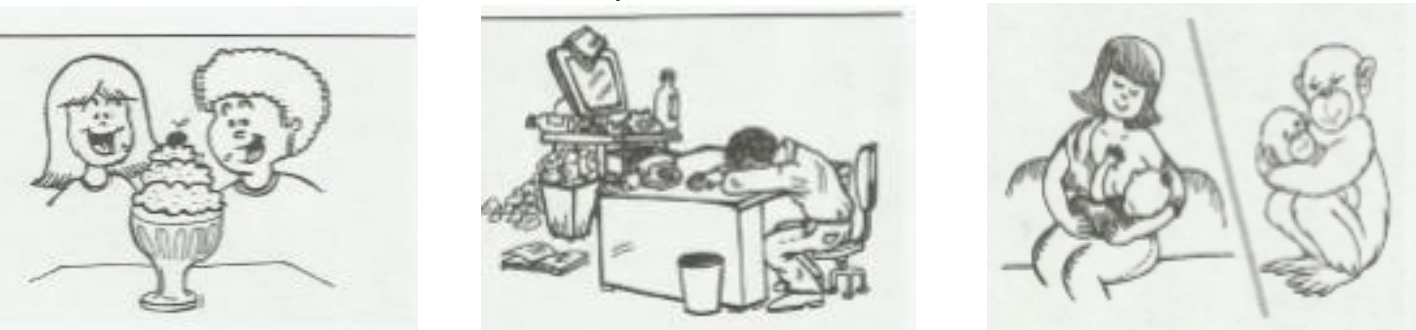

Fonte: Brandão (2011, p. 547, p. 469 e p. 468).

Descrição da imagem: figura ilustrativa dos verbetes "prazer, negligente e natural" em Brandão (2011), proporcionando aos leitores deste trabalho a possibilidade de compreender melhor a análise realizada.

Ao visualizar as ilustrações acima, podemos perceber que elas não nos remetem ao real significado das entradas ou à sua totalidade de sentidos. No verbete "natural", a definição apresentada pela obra é "aquilo que é normal" (BRANDÃO, 2011, p. 468); desta forma, percebemos parcialmente uma relação entre enunciado lexicográfico e ilustração, atuando esta como auxílio na compreensão do verbete pelos consulentes, mas não na sua completude. Por este motivo, entendemos que as ilustrações presentes em vários verbetes do DIL não são fidedignas aos conceitos expressos pelas entradas.

Além disso, nota-se a utilização de uma mesma ilustração para diferentes entradas, como nos verbetes "nuvem" e "nublado", que portam dessemelhanças em seus semas e, por este motivo, deveriam ter ilustrações distintas: 


\section{_tı.}

Cotejo entre dois dicionários de Libras: análise de microparadigmas Leandro Andrade Fernandes • Vanessa Regina Duarte Xavier

Figura 8: Verbete "nuvem".

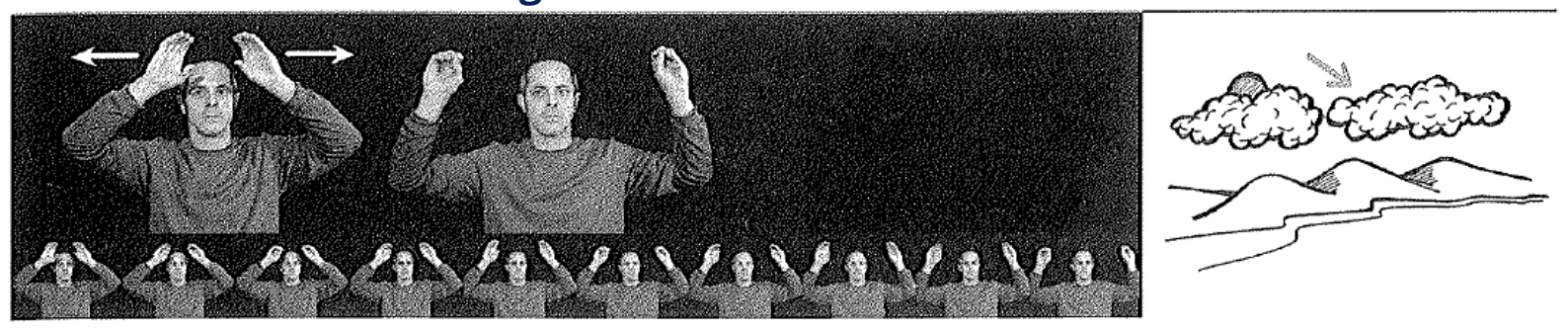

NUVE fechando um pouco as mãos, sem dobrar os dedos, e abrindo-as novamente várias vezes durarite o percurso.

- Muvem: Agonerado de gotas minusculas da água ou cristais de gelo suspenses no ar.

Fonte: Brandão (2011, p. 477).

Descrição da imagem: figura ilustrativa do verbete "nuvem" em Brandão (2011), proporcionando aos leitores deste trabalho a possibilidade de compreender melhor a análise realizada.

Figura 9: Verbete "nublado".
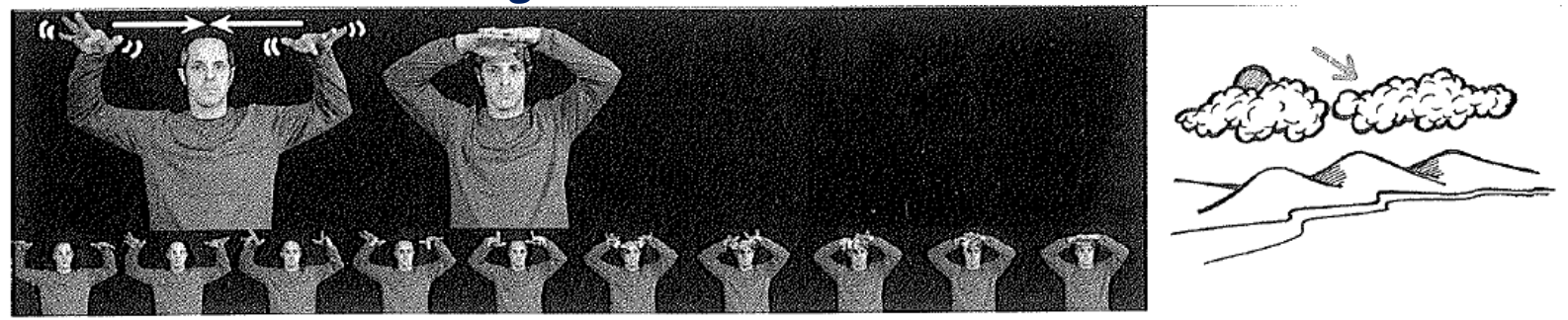

MUBLADO - Māos aberias, dedos separados apontando para a frente, paimas para baixo. Posicionar as māos na altura da cabeça e move-las simultaneamente, unindo-as (una sobre a outra) acima da cabeca. Movimentar totos os decios aleatoriamente durante o percurso.

- Nublado: Cheio de naveris; nebuloso. Sinal igual: Mebuloso

Fonte: Brandão (2011, p. 476).

Descrição da imagem: figura ilustrativa do verbete "nublado" em Brandão (2011), proporcionando aos leitores deste trabalho a possibilidade de compreender melhor a análise realizada.

Um ponto positivo a se destacar em algumas ilustrações é a aplicação do recurso "rótulo de diferenciação", proposto por Stein (1991, apudSILVA 2006, p. 62), que o define como "elemento verbal que apoia ilustrações relativas a nomes contáveis que se referem a objetos possuidores da característica unívoca.". Nestes casos, o DIL faz o uso deste recurso, mas não o explica, de modo a delimitar, na ilustração, a parte do todo, quando esta é definida em uma determinada entrada, como pode ser observado no verbete "parede", a seguir: 


\section{_tı.}

Cotejo entre dois dicionários de Libras: análise de microparadigmas

Leandro Andrade Fernandes • Vanessa Regina Duarte Xavier

Figura 10: Verbete "parede".
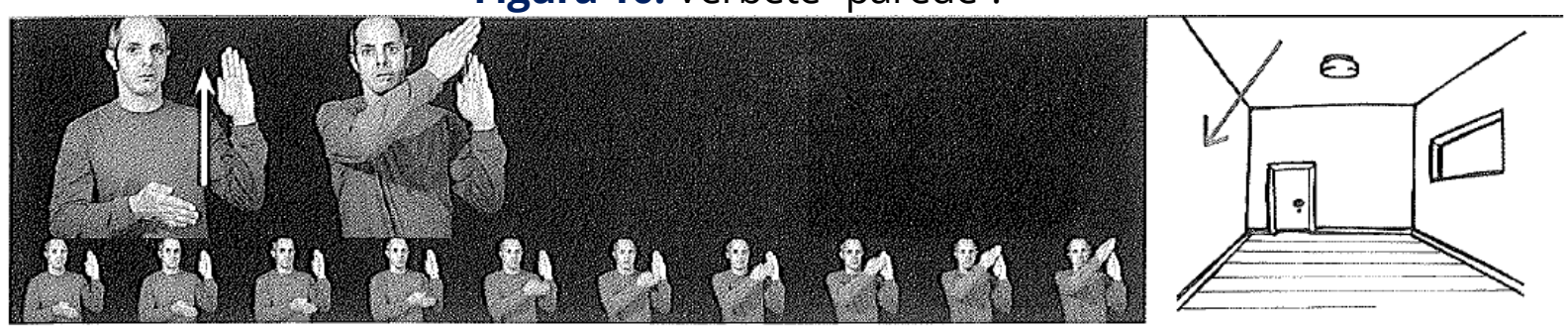

PABL DE -- Mão esquerda aberta, dedos unidos e esticados apontando para cima, palma para dentro. Mão direita aberta, dedos unidos e esticados apontando para a frente. Posicionar as mã̃os

contorme a foto 1. En seguida, mover a mão direita para cinta, resvalando levemente pelo braço esquerdo, do cotovelo atè as pontas dos dedos.

Fonte: Brandão (2011, p. 509).

Descrição da imagem: figura ilustrativa do verbete "parede" em Brandão (2011), proporcionando aos leitores deste trabalho a possibilidade de compreender melhor a análise realizada.

É interessante pontuar que este dicionário não faz uso de siglas e/ou abreviaturas no corpo do verbete, recurso este presente em quase todos os dicionários. Podemos justificar este fato por não conterem os verbetes, no enunciado lexicográfico, a classe gramatical, as marcas de uso, entre outros, pois estes elementos geralmente são adicionados ao corpo do verbete na sua forma abreviada. No DIL, o único microparadigma abstrato presente no corpo do verbete é o sinal igual, como pode ser observado na imagem "parede".

Passemos agora para a análise do DEIT. Em relação aos elementos que compõem o verbete, Capovilla, Raphael e Mauricio (2013, p. 47) apresentam em seus textos externos a seguinte estrutura:

Quadro 2: Estrutura base do verbete no DEIT.

\begin{tabular}{|c|l|l|}
\hline Legenda & \multicolumn{1}{|c|}{ Elemento } & \multicolumn{1}{|c|}{ Definição/explicação } \\
\hline 1 & $\begin{array}{l}\text { llustração precisa da forma } \\
\text { do sinal }\end{array}$ & $\begin{array}{l}\text { "Tal ilustração permite uma melhor } \\
\text { compreensão da sequência temporal das } \\
\text { unidades sublexicais que compõem o sinal". }\end{array}$ \\
\hline 2 & $\begin{array}{l}\text { llustração do significado do } \\
\text { sinal }\end{array}$ & $\begin{array}{l}\text { "Tais ilustrações de significação permitem à } \\
\text { criança surda apreender diretamente o sentido }\end{array}$ \\
\hline
\end{tabular}




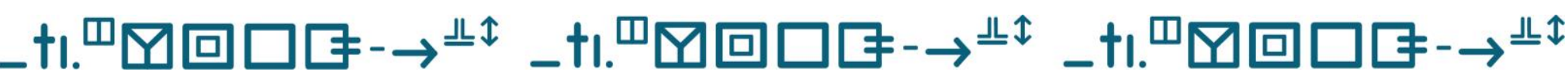

Cotejo entre dois dicionários de Libras: análise de microparadigmas

Leandro Andrade Fernandes • Vanessa Regina Duarte Xavier

\begin{tabular}{|c|c|c|}
\hline & & $\begin{array}{l}\text { do sinal sem depender do Português, e facilitam } \\
\text { a memorização do sinal e dos verbetes em } \\
\text { Português e Inglês, bem como o seu uso no dia } \\
\text { a dia". }\end{array}$ \\
\hline 3 & Escrita em SignWriting & $\begin{array}{l}\text { "A leitura dos sinais escritos em SignWriting } \\
\text { sinaliza diretamente à mente do surdo, assim } \\
\text { como a decodificação da escrita alfabética fala } \\
\text { diretamente à mente do ouvinte". }\end{array}$ \\
\hline 4 & Soletração digital do sinal & $\begin{array}{l}\text { "A soletração digital auxilia a criança a penetrar } \\
\text { na composição GrafÊmica ou Scriptumlcular das } \\
\text { palavras escritas, quebrando as palavras escritas } \\
\text { em suas letras componentes, e vertendo as } \\
\text { letras em formas de mãos individuais". }\end{array}$ \\
\hline 5 & $\begin{array}{l}\text { Verbete em português e em } \\
\text { Inglês }\end{array}$ & $\begin{array}{l}\text { "Tais verbetes correspondem ao sinal e } \\
\text { permitem indexar alfabeticamente os sinais e } \\
\text { traduzir de Libras para o Português e o Inglês". }\end{array}$ \\
\hline 6 & Validade do sinal & $\begin{array}{l}\text { "O escopo da validade do sinal em termos do(s) } \\
\text { estado(s) brasileiro(s) em que esse sinal é, com } \\
\text { certeza, empregado corretamente". }\end{array}$ \\
\hline 7 & $\begin{array}{l}\text { Classe gramatical dos } \\
\text { verbetes em Português }\end{array}$ & $\begin{array}{l}\text { "Tal classificação permite ao surdo compreender } \\
\text { o comportamento das palavras do Português e } \\
\text { aprender a usá-las adequadamente". }\end{array}$ \\
\hline 8 & Definição & $\begin{array}{l}\text { "Tal definição permite ao surdo aumentar o seu } \\
\text { conhecimento do mundo, bem como de Libras, } \\
\text { do Português e do Inglês". }\end{array}$ \\
\hline 9 & Exemplo & $\begin{array}{l}\text { "Tais exemplos permitem ao surdo usar } \\
\text { corretamente as palavras do Português } \\
\text { correspondentes aos sinais de Libras: e, ao } \\
\text { ouvinte, usar corretamente os sinais de Libras } \\
\text { correspondente às palavras". }\end{array}$ \\
\hline 10 & Etimologia/morfologia & $\begin{array}{l}\text { "Descrição etimológica a partir da análise de sua } \\
\text { estrutura MorfÊmica, ou seja, dos MorfÊmica } \\
\text { (Formículos) metafóricos moleculares que o } \\
\text { compõem, e uma breve análise do parentesco } \\
\text { semântico entre sinal e vários outros sinais que } \\
\text { compartilham alguns dos mesmos MorfÊmas ou } \\
\text { Formículos moleculares". }\end{array}$ \\
\hline 11 & Iconicidade & $\begin{array}{l}\text { "De como o sinal materializa o significado } \\
\text { defronte os olhos do observador. Tal descrição } \\
\text { permite ao observador aprender esse } \\
\text { significado de um modo fenomenologicamente } \\
\text { imediato". }\end{array}$ \\
\hline 12 & Descrição detalhada do sinal & $\begin{array}{l}\text { "A descrição detalhada e sistemática da forma do } \\
\text { sinal. Juntamente com a ilustração, tal descrição } \\
\text { permite ao leigo reproduzir fielmente cada sinal } \\
\text { de Libras". }\end{array}$ \\
\hline
\end{tabular}

Fonte: Elaborado pelos autores com base em Capovilla; Raphael e Mauricio (2013, p. 47-48). 


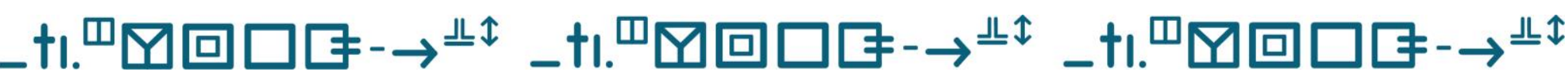

Cotejo entre dois dicionários de Libras: análise de microparadigmas Leandro Andrade Fernandes • Vanessa Regina Duarte Xavier

Descrição da imagem: quadro informativo elaborado pelos autores com base em Capovilla; Rafhael e Mauricio (2013), elucidando os doze microparadigmas e suas definições presentes nos verbetes do dicionário em questão.

Os autores afirmam que os verbetes possuem no mínimo dez (10) dos doze (12) microparadigmas. Em relação à estrutura dos verbetes Capovilla, Raphael e Mauricio (2013, p. 50) apontam que, “[...] começa com a soletração manual do verbete em português que corresponde ao sinal da entrada". Interessante observar que a utilização da soletração manual faz com que evidencie a LP e não a Libras, pois "este leva em consideração elementos grafemáticos da língua portuguesa e não da Libras" (FERNANDES; XAVIER, 2019, p. 9).

De certa forma, há um padrão na organização dos verbetes, mas, em algumas entradas, o verbete é iniciado com a ilustração e não com a datilologia, apresentando esta variação na cabeça do verbete, a qual ora se inicia pela lexia transliterada para a Libras, ora pela ilustração precisa da forma do sinal.

Há um total de doze (12) elementos compondo o verbete do DEIT, dentre os quais os autores afirmam que cada verbete faz o uso de pelo menos dez (10). 0 item 1 equivale à representação do sinal servindo-se da ilustração, recurso muito utilizado na descrição lexical da Libras. Conforme mencionado anteriormente, alguns verbetes se iniciam com a ilustração, destoando da organização de referência, apresentada nos textos externos.

Como a imagem é importante para a compreensão dos surdos e demais usuários da Libras na tradução de itens lexicais da língua oral para a Libras, é fundamental que tais ilustrações sejam inequívocas, oferecendo ao consulente informações o mais próximas possível dos verbetes a que se referem. Desta forma, os autores apontam que a ilustração do significado do sinal tem o objetivo de "permitir à criança surda compreender diretamente o sentido do sinal ou significado do sinal sem depender da leitura do português" e 


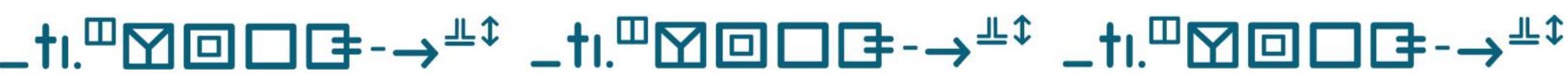

Cotejo entre dois dicionários de Libras: análise de microparadigmas Leandro Andrade Fernandes • Vanessa Regina Duarte Xavier

acrescentam que "[...] representar o significado de um sinal é precisamente o objetivo maior da ilustração de significado do presente Novo DEIT, de modo a permitir ao consulente, surdo ou não, principalmente o ainda não alfabetizado, compreender diretamente o significado de um sinal por meio da inspeção do sinal" (CAPOVILLA; RAPHAEL; MAURICIO, 2013, p. 50).

No entanto, o uso de ilustrações em todos os verbetes pode ocasionar alguns problemas, uma vez que nem sempre elas oferecem ao consulente um significado fidedigno e, às vezes, reduzem os conceitos por eles expressos, como se cada verbete tivesse exatamente um único sentido. Possibilitam, assim, interpretações errôneas caso o consulente não recorra à definição e ao exemplo em LP. Casos como estes podem ser observados nas entradas: "autorizar" (CAPOVILLA; RAPHAEL; MAURICIO, 2013, p. 457), "besteira" (CAPOVILLA; RAPHAEL; MAURICIO, 2013, p. 524), "bronquite" (CAPOVILLA; RAPHAEL; MAURICIO, 2013, p. 578), entre outros, como demonstram as imagens da Figura 11 a seguir:

Figura 11: Ilustrações dos verbetes "autorizar", "besteira” e "bronquite”, respectivamente.
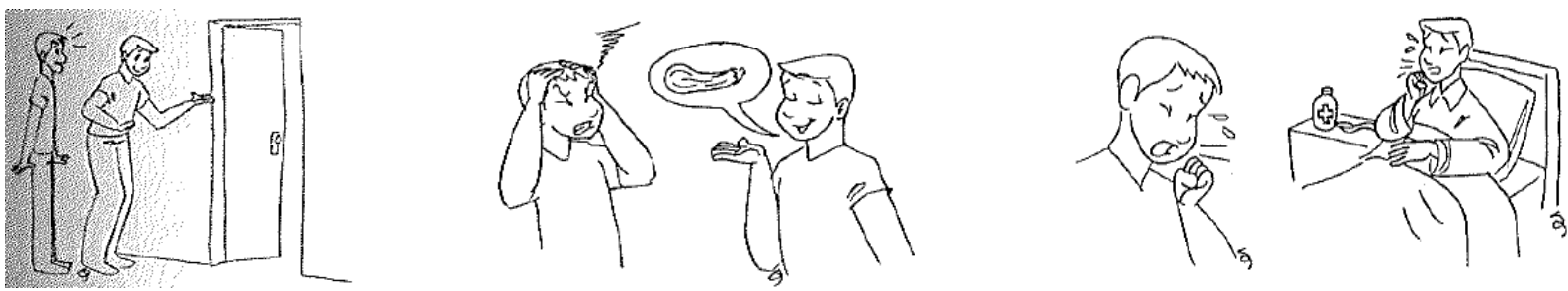

Fonte: Capovilla, Raphael e Mauricio (2013, p. 457, p. 524 e p. 578).

Descrição da imagem: figura ilustrativa dos verbetes "autorizar, besteira e bronquite" em Capovilla; Raphael e Mauricio (2013), proporcionando aos leitores deste trabalho a possibilidade de compreender melhor a análise realizada.

Assim como o DIL, o DEIT faz o uso do recurso de setas, rótulo de diferenciação, como pode ser encontrado nos sinais: "alfinete" (CAPOVILLA; RAPHAEL; MAURICIO, 2013, p. 323), "bisturi" (CAPOVILLA; RAPHAEL; MAURICIO, 


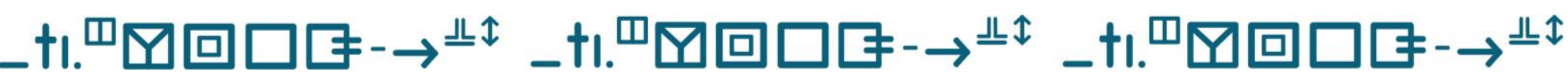

Cotejo entre dois dicionários de Libras: análise de microparadigmas Leandro Andrade Fernandes • Vanessa Regina Duarte Xavier

2013, p. 536), "canudo" (CAPOVILLA; RAPHAEL; MAURICIO, 2013, p. 641) e outros, de forma a levar o consulente a uma discriminação da parte em relação ao todo descrito pela imagem.

Figura 12: llustrações dos verbetes "alfinete", "bisturi" e "canudo", respectivamente.
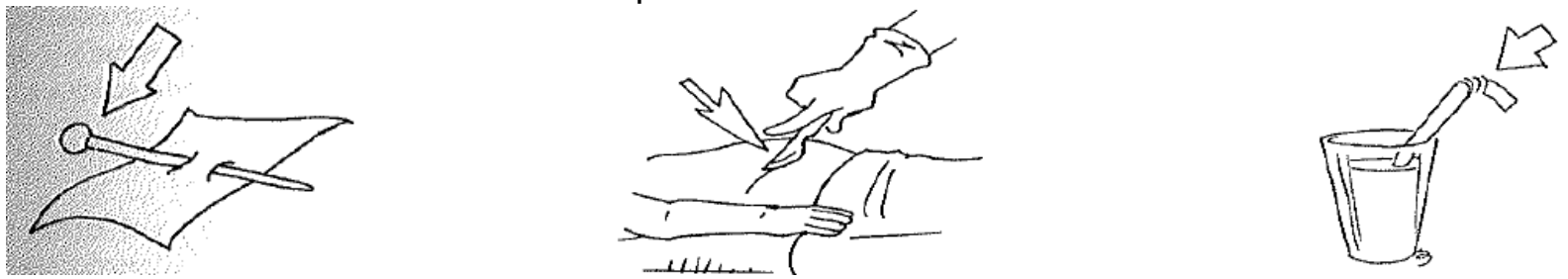

Fonte: Capovilla, Raphael e Mauricio (2013, p. 323, p. 536 e p. 641).

Descrição da imagem: figura ilustrativa dos verbetes "alfinete, bisturi e canudo" em Capovilla; Raphael e Mauricio (2013), proporcionando aos leitores deste trabalho a possibilidade de melhor compreender a análise realizada.

Entretanto, há casos em que nem mesmo o recurso proposto por Stein (1991) consegue sanar tais necessidades, como evidenciam os exemplos a seguir:

Figura 13: Ilustrações dos verbetes "bissexual", "fisionomia" e "gloriar-se", respectivamente.
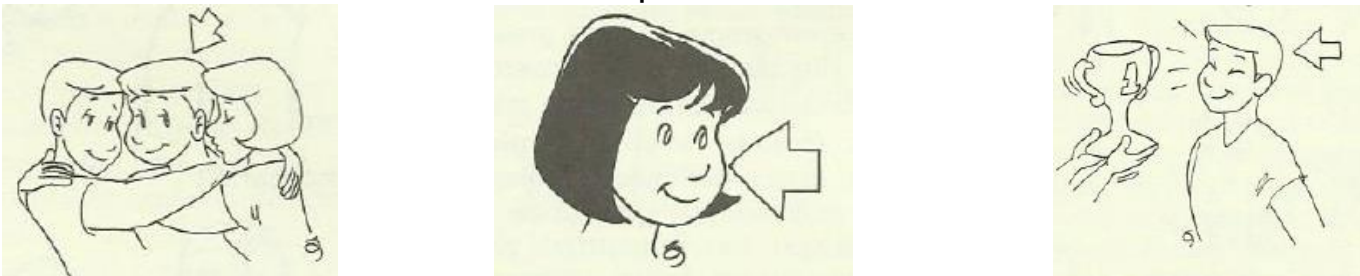

Fonte: Capovilla, Raphael e Mauricio (2013, p. 536, p. 1275 e p. 1343).

Descrição da imagem: figura ilustrativa dos verbetes "bissexual, fisionomia e gloriar-se" em Capovilla; Raphael e Mauricio (2013), proporcionando aos leitores deste trabalho a possibilidade de melhor compreender a análise realizada.

Como apresentado anteriormente, compartilhamos a ideia de que a ilustração é um recurso importante na compreensão do significado pelo sujeito surdo, no entanto, em algumas unidades linguísticas, este recurso pode levar à 


\section{_tı.}

Cotejo entre dois dicionários de Libras: análise de microparadigmas Leandro Andrade Fernandes • Vanessa Regina Duarte Xavier

uma interpretação errônea do significado do verbete, tornando-a ambígua. Por este motivo, defendemos a não utilização de ilustrações em todos os verbetes em dicionários de Libras, pois, nem todos os verbetes precisam ser ilustrados, já que as ilustrações parecem relevantes em entradas com acepções unívocas, e prejudiciais nas entradas em que é possível mais de uma interpretação.

O DEIT utiliza para a representação gráfica da Libras o sistema SignWriting, porém o mesmo não é aproveitado para a organização semasiológica das entradas pela escrita, respeitando a sequência alfabética da LP. Até o presente momento, não há no SignWriting uma forma de organização dos elementos fonológicos das LS que possibilite a ordenação semasiológica das entradas em dicionários, glossários ou qualquer outro instrumento que vise à compilação de corpora destas línguas.

Por sua vez, o item soletração do sinal é utilizado no dicionário como forma de organização dos verbetes. A soletração manual é um empréstimo linguístico que as LS realizam das línguas orais de seus respectivos países. Apesar de ser um recurso válido para apresentar a entrada em Libras, este artifício organiza as entradas em ordem semasiológica das línguas orais, e não das LS. Portanto, o DEIT é um dicionário em ordem semasiológica que leva em consideração os elementos fonológicos da LP, usufruindo do recurso da datilologia para alcançar este objetivo. Interessante observar que, em algumas entradas, a soletração manual não corresponde, em sua plenitude, ao equivalente na LP, como pode ser observado a seguir:

Figura 14: Verbete "estação de metrô Santa Cruz". 


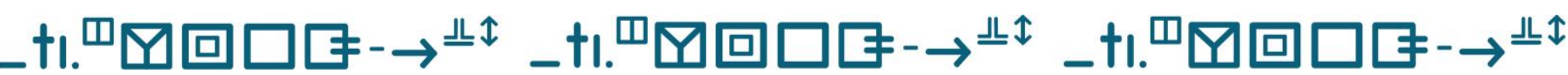

Cotejo entre dois dicionários de Libras: análise de microparadigmas Leandro Andrade Fernandes • Vanessa Regina Duarte Xavier
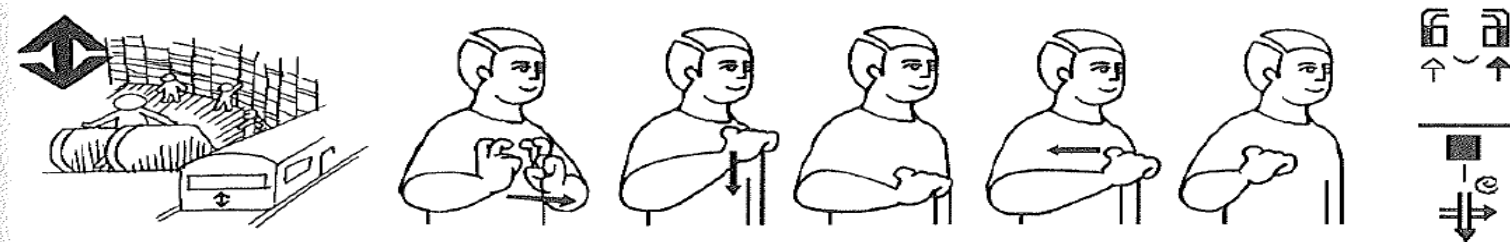

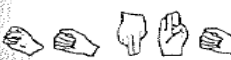

ही 8 ही

estạ̧ão de metrô Santa Cruz (1) (São Paulo, SP) (sinal usado em: SP) aço de metrô da Linha Azul (Norte-Sul) localizada no bairro Vila Clementino, na inal de ônibus na estação de metrô Santa Cruz. (Fazer este sinal Metrô: Māos em 5, palma a palma, próximas uma à outra. Movê-las para frente com força, duas vezes. Então, māo fechada, palma para baixo, polegar distendido para trás. Mover a māo sobre o peito de cima para baixo e da esquerda para a direita, descrevendo uma cruz.)

Fonte: Capovilla, Raphael e Mauricio (2013, p. 1145).

Descrição da imagem: figura ilustrativa do verbete "estação de metrô Santa Cruz" em Capovilla; Raphael e Mauricio (2013), proporcionando aos leitores deste trabalho a possibilidade de compreender melhor a análise realizada.

Considerando a figura acima, com ênfase na datilologia, notamos que há apenas a referência ao termo específico, enquanto no equivalente em português há o termo genérico seguido pelo termo específico. Situações como esta podem ser encontradas em grande escala em entradas toponímicas ${ }^{12}$, como estações de metrô e nomes de bairros. Apontamos aqui a falta de rigor, pois se é esta a entrada e seu equivalente, carecem de uma padronização em que se utilize ou não o termo genérico em ambos os elementos. Além disso, não há rigor na organização das entradas, uma vez que o exemplo acima está localizado na lista dos verbetes iniciados com a letra " $E$ ", e a entrada começa com a letra "S" de "Santa Cruz" - se seguirmos fielmente a orientação dos autores de que a datilologia (soletração manual) se refere à entrada - e não com a letra "E", de "Estação de Metrô Santa Cruz". Concluímos, assim, que a soletração manual é algo secundário, e que a organização do dicionário se dá pela escrita da LP.

12 Castiglione (2014, p. 12) define a toponímia como “[...] o estudo dos nomes próprios de lugares, ou seja, os topônimos. Além do estudo linguístico de um nome, a pesquisa toponímica estabelece relações entre a cultura e a história do lugar, ou seja, realiza uma pesquisa abrangente em que se analisam aspectos geográficos, históricos, sócioeconômicos e linguísticos que permitam ao estudioso descobrir a origem e a motivação de determinado topônimo". 


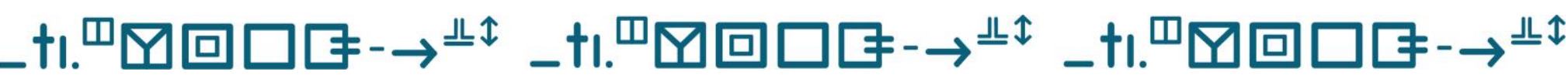

Cotejo entre dois dicionários de Libras: análise de microparadigmas Leandro Andrade Fernandes • Vanessa Regina Duarte Xavier

É pertinente ressaltar a duplicidade de lematização dos verbetes toponímicos relativos a bairros, que podem ser encontrados em entradas iniciadas pelo termo específico seguido pelo genérico e apenas com o termo específico, a exemplo do lexema "Bairro Santo Amaro" (CAPOVILLA; RAPHAEL; MAURICIO, 2013, p. 480), reprisado no verbete "Santo Amaro" (CAPOVILLA; RAPHAEL; MAURICIO, p. 2226). Destacamos aqui que, apesar da tentativa de organização das entradas pelo recurso da datilologia, este ainda se dá pelo equivalente na LP, como pode ser observado nas ilustrações a seguir:

Figura 15: Verbete "bairro Santo Amaro".

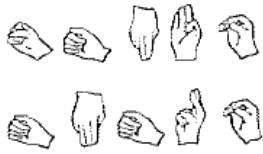
Santo Amaro (São Paulo, $\mathbf{S P}$ ) (sinal usado em: $\mathbf{S P}$ ) (inglês: Santo Amaro

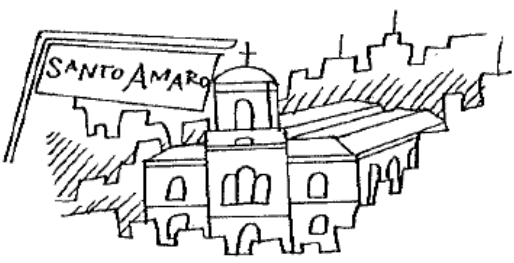

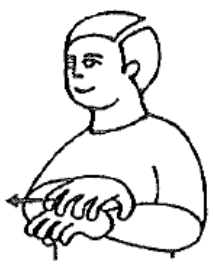
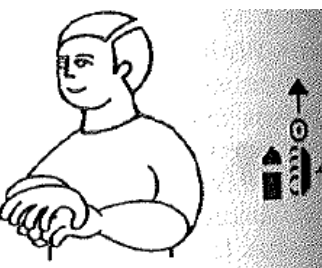
neighborhood): Bairro da zona sul da cidade de São Paulo. Ex.: O Largo Treze fica no bairro Santo Amaro. (Māos abertas, palmas para bake cona sul da cidade digeiramente a māo direita para trás, passancio pontas dos dedos no dorso da mão esquerda.)

Fonte: Capovilla; Raphael e Mauricio (2013, p. 480).

Descrição da imagem: figura ilustrativa do verbete "bairro Santa Amaro" em Capovilla; Raphael e Mauricio (2013), proporcionando aos leitores deste trabalho a possibilidade de compreender melhor a análise realizada.

Figura 16: Verbete "Santo Amaro".

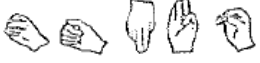

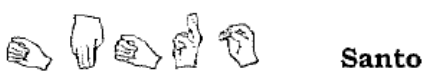

Amaro (1) (bairro de São Paulo, SP) (sinal usado em: SP) (inglês: Santo Amaro neighborhood): Bairro

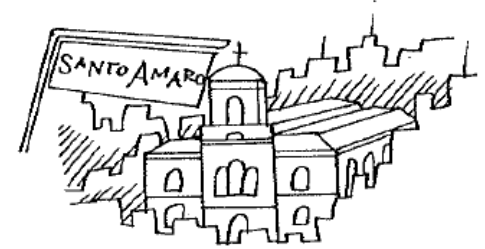

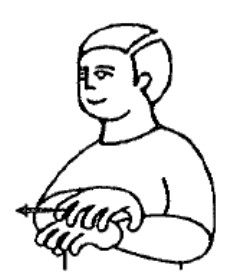
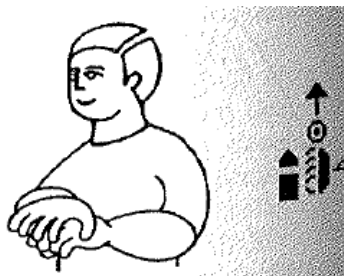

localizado na zona sul da cidade de Säo Paulo. Ex: A estátua do bandeirante Borba Gato é um dos marcos de entrada do bairro San na zona sul da cidade de São Paulo. Ex.: A estátua do bandeirante Borba Gato é um dos mar este sinal Birrio Santo Santo Amaro. Ex.: Em Santo Amaro localiza-se a Unisa, Universidade de Santo Amaro. (Fazer este sinarda. More ligeiramente a māo direita para trás, passando as pontas dos dedos no dorso da mão esquerda.)

Fonte: Capovilla, Raphael e Mauricio (2013, p. 2226).

Descrição da imagem: figura ilustrativa do verbete "Santo Amaro" em Capovilla; Raphael e Mauricio (2013), proporcionando aos leitores deste trabalho a possibilidade de compreender melhor a análise realizada. 


\section{_tı.}

Cotejo entre dois dicionários de Libras: análise de microparadigmas Leandro Andrade Fernandes • Vanessa Regina Duarte Xavier

Entendemos que a correspondência do item lexical em português e em inglês refere-se ao elemento equivalente das entradas em Libras. O item validação do sinal, representado em forma de siglas, caracteriza a marca de uso, pois indica onde, geograficamente, o sinal é utilizado.

Apontamos que a marca de uso disposta para informar ao consulente em que região do Brasil o sinal é utilizado não é confiável, pois faltam informações precisas que indiquem os corpora usados como fonte para a constituição da nomenclatura presente no dicionário. Além de que, ao apontar que determinado sinal é realizado em uma determinada região, pode levar o leitor a entender que este não é utilizado em outras regiões.

Assim como a validação do sinal, a classe gramatical é representada por abreviaturas, recurso este também utilizado em dicionários de línguas orais. Os microparadigmas definição e exemplos são dispostos em todos os verbetes, no entanto, para conceder maior mérito científico ao dicionário, seria necessário informar as fontes destas informações.

Dubois et al(2006, p. 251) definem etimologia como "[...] a pesquisa das relações que uma palavra mantém com outra unidade mais antiga, de que se origina". Portanto, é comum os dicionários de línguas orais evidenciarem na etimologia dados referentes à origem da lexia, assim como as mudanças em nível diacrônico destas unidades. No item etimologia presente no DEIT, não há estas informações, mas sim uma amostragem resumida dos sinais que compartilham os mesmos morfemas, como pode ser observada a seguir:

Figura 17: Verbete "horizontal". 


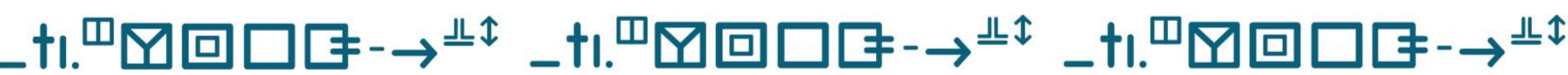

Cotejo entre dois dicionários de Libras: análise de microparadigmas

Leandro Andrade Fernandes • Vanessa Regina Duarte Xavier

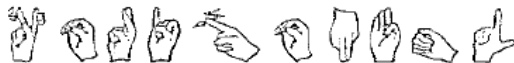

horizontal (sinal usado em: $\mathbf{S P}$, SC, $R S$ ) (sinal usado em: $\mathbf{S P}$ ) (inglês: horizontal, parallel to the horizon): adj. $m$. ef. Paralelo ou relativo ao horizonte. Perpendicular à vertical do lugar de observação. Deitado ao comprido. Ex.:
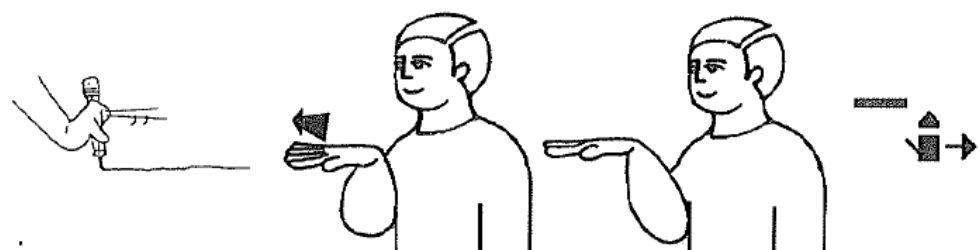

Se a pessoa sentir tontura devido à pressão baixa, ela deve se colocar em posição horizontal, com o coração e o encéfalo na mesma altura. (Māo aberta, palma para baixo, dedos apontando para frente, em frente ao corpo. Movê-la para a direita.) Etimologia. Morfologia: Trata-se de sinal formado por morfema metafórico molar que representa formas e elementos geométricos, como nos sinais ClRCULO, QUADRADO, OVAL, REDONDO, RETẢNGULO, TRIÂNGULO, e acentuação gráfica, como no sinal PONTO, em que o dedo indicador distendido se move a partir de um ponto e completa a trajetória descrevendo a forma geométrica ou sua orientaçāo em relaçāo aos planos, como nos sinais HORizONTAL e VERTiCAL, ou caracteres de acentuaçăo, como nos sinais ACENTO AGUDO, ACENTO GRAVE, ACENTO CIRCUNFLEXO, DOIS PONTOS, PONTO, PONTO DE EXCLAMAÇÃO, PONTO DE INTERROGAÇÃO, TRAVESSÃO, e PORCENTAGEM. Iconicidade: No sinal HORIZONTAL, o sinalizador tem a māo aberta, e a movimenta para o lado, indicando o eixo horizontal $\mathrm{X}$ o plano horizontal (XZ)

Fonte: Capovilla; Raphael e Mauricio (2013, p. 1396).

Descrição da imagem: figura ilustrativa do verbete "horizontal" em Capovilla; Raphael e Mauricio (2013), proporcionando aos leitores deste trabalho a possibilidade de compreender melhor a análise realizada.

No verbete acima, podemos apontar também a iconicidade, elemento que representa a motivação presente na criação do sinal, assim como ocorre nas línguas orais, embora tal informação não conste em dicionários gerais destas línguas. Nota-se, assim, que nestas línguas a motivação ocorre em menor grau do que nas LS, conforme aponta Nascimento (2016, p. 27): “A motivação visual nas LS ocorre em larga escala, já que se trata de uma língua de modalidade espacial e visual". Este microparadigma é utilizado unicamente no DEIT e em muitas entradas é possível perceber o uso deste com outra finalidade, como mostra a imagem a seguir:

Figura 18: Verbete "ideia".

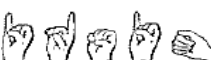

(sinal usado em: SP) (ing thought, mental image or concept, concept, imagination, plan, opinion, project, model): Idem ideia (1). Ex.: A ideia de fazer 0 dicionário de lingua de sinais é

muito boa. (Māo em 1, palma para frente, com a ponta do indicador tocando o lado direito da testa. Mover a mão para frente e para a direita, curvando o indicador e arregalando os olhos.) Etimologia. Morfologia: Trata-se de sinal formado pelo morfema Mente (Atividade Cognitiva e Intelectual) codificado pelo local de sinalização na região da cabeça, como nos sinais ADIVINHAR, COMPREENDER, CONVENCER, CRER - ACREDITAR, CULTURA (DESENVOLVER A MENTE, ABRIR A MENTE), DECORAR - MEMORIZAR (APRENDER DE COR), ESPERTEZA, ESTÓRIA, FILOSOFAR - TEORIA, e DECIDIR. Iconicidade: No sinal IDEIA COm a mão em 1, a ponta do indicador toca a lateral da testa e se move para cima, enquanto o indicador se curva e os olhos se arregalam.

Fonte: Capovilla, Raphael e Mauricio (2013, p. 1423). 


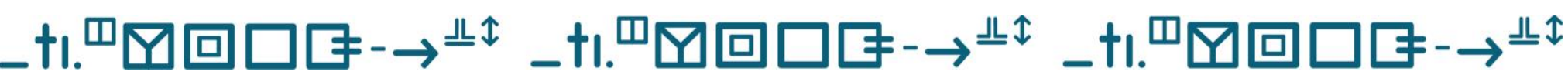

Cotejo entre dois dicionários de Libras: análise de microparadigmas Leandro Andrade Fernandes • Vanessa Regina Duarte Xavier

Descrição da imagem: figura ilustrativa do verbete "ideia" em Capovilla; Raphael e Mauricio (2013), proporcionando aos leitores deste trabalho a possibilidade de compreender melhor a análise realizada.

A exemplo da figura acima, em uma quantidade significativa de entradas, a iconicidade representa o modo como o sinal é realizado e não a sua motivação. Percebe-se que a informação atribuída na descrição do sinal é a mesma presente no item iconicidade, com algumas reformulações textuais.

Como pôde ser observado, assim como há diferenças estruturais relacionadas às diversas informações sobre o lema-entrada em diferentes dicionários de língua portuguesa, o mesmo ocorre em dicionários de Libras. Esta é uma circunstância comum, visto que é importante o estabelecimento de critérios específicos para cada obra e que tais elementos se harmonizem com a sua proposta lexicográfica e seu público-alvo. Contudo, análises metalexicográficas são cruciais não apenas para o estudo da organização de um dicionário e da sua coerência na aplicação dos critérios utilizados, mas também para servir como base para o aprimoramento de futuras obras dicionarísticas, minimizando, assim, problemas tanto no nível linguístico quanto lexicográfico.

\section{Considerações finais}

Assim como na LP, diferentes obras lexicográficas estão sendo produzidas, sejam elas impressas ou digitais, necessitando, assim, de estudos metalexicográficos, relacionados ao uso, avaliação e história dos dicionários, dentre outros elementos. Contudo, percebe-se que, apesar de os dicionários apresentarem uma estrutura inicial, os verbetes variam, podendo ora apresentar os elementos indicados em textos externos, e ora não.

O DIL apresenta como entrada o lema em LP, enquanto o DEIT utiliza a soletração manual em Libras, com base no alfabeto latino da LP; no entanto, em vários verbetes, é a ilustração e não a soletração manual que desempenha 


\section{_tı.}

Cotejo entre dois dicionários de Libras: análise de microparadigmas Leandro Andrade Fernandes • Vanessa Regina Duarte Xavier

esta função. Além disso, entendemos o DIL como um dicionário bilíngue por fazer uso da LP e da Libras e o DEIT trilíngue, utilizando a LP, a Libras e a língua inglesa - como designado pelos autores, admitindo como língua-alvo a Libras. Convém assinalar que apenas o DEIT aplica os elementos: escrita em SignWriting, etimologia, iconicidade, datilologia, sinal em inglês e classe gramatical.

Como observado, alguns destes microparadigmas não são utilizados como carecem, por exemplo, no item etimologia, surpreendemo-nos com a presença de uma descrição icônica, similarmente ao elemento iconicidade, mas com algumas reformulações em seu texto. Além da utilização randômica da ilustração, que em profusos verbetes não facultam ao consulente o auxílio que evocariam, outro ponto é a tentativa de organização do léxico da Libras em ordem alfabética da LP, no DIL (2011), e com base no recurso datilológico, no DEIT (2013), que mesmo tratando da representação pela CM, não reflete os elementos fonológicos das LS.

Em suma, entendemos que o verbete necessita de uma estrutura fixa, concedendo, assim, um padrão para a obra. Apesar de a ilustração ser importante no tocante à LS, não é recomendado que todos os verbetes a possuam, já que verbos, adjetivos, dentre outras classes de palavras, ao portarem esse microparadigma, podem ocasionar uma interpretação errônea. Pelo exposto, esperamos que este estudo possa contribuir para os estudos (meta)lexicográficos, em especial voltados para as LS.

\section{Referências}

ANDRADE, Maria Margarida. Lexicologia, terminologia: definições, finalidades, conceitos operacionais. In: OLIVEIRA, Ana Maria P. P. de; ISQUERDO, Aparecida 


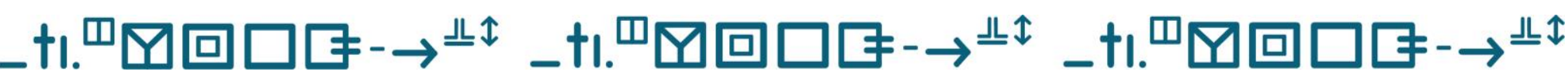

Cotejo entre dois dicionários de Libras: análise de microparadigmas

Leandro Andrade Fernandes • Vanessa Regina Duarte Xavier

N. (Org.). As ciências do léxico: lexicologia, lexicografia, terminologia. Campo Grande: Editora da UFMS, 1998. p. 89-98.

BALDINGER, Kurt. Teoría semántica: hacia una semántica moderna. Trad. Emilio Lledó; L. Molina; José Mondéjar; José Luis Rivarola. Madrid: Alcalá, 1970.

BORBA, Francisco da Silva. Conversando com quem faz prática lexicorgafica. In. XATARA, Claudia; BEVILACQUA, Cleci Regina; HUMBLÉ, Fhilippe René Marie. (org.). Dicionários na teoria e na prática: como e para quem são feitos. São Paulo: Parábola Editorial, 2011.

BRANDÃO, Flavia. Dicionário Ilustrado de Libras: língua brasileira de sinais. São Paulo: Global, 2011.

CAPOVILLA, Fernando Cesar; RAPHAEL, Walkiria Duarte; MAURICIO, Aline Cristina L. Novo DEIT-Libras: Dicionário Enciclopédico Ilustrado Trilíngue da Língua de Sinais Brasileira. 3. ed. São Paulo: Edusp, 2013. 2 v.

CARVALHO, Maria Aparecida Holanda Delmondes. A língua brasileira de sinais - Libras: uma análise sobre os parâmetros para a aquisição da linguagem e aprendizagem da pessoa com surdez. In. SANTOS, Luciana de Jesus Botelho Sodré dos et al. Educação especial, inclusiva em contexto. Campina Grande: Editora $2021 . \quad$ Disponível em: https://ampllaeditora.com.br/books/2021/04/EducacaoEspeciallnclusiva.pdf\#p age=33. Acesso em: 13 nov. 2021

CASTIGLIONI, Ana Claudia. Dicionário enciclopédico de topônimos do estado de Mato Grosso do Sul: uma proposta de modelo. 234 f. Tese (doutorado em Estudos Linguísticos) Universidade Estadual Paulista - UNESP: São José do Rio Preto, 2013. Disponível em: https://repositorio.unesp.br/handle/11449/110528. Acesso em 13 nov. 2014.

DUBOIS, Jean et al. Dicionário de linguística. trad. Frederico pessoa de Barros et al. São Paulo: Cultrix, 2006. 


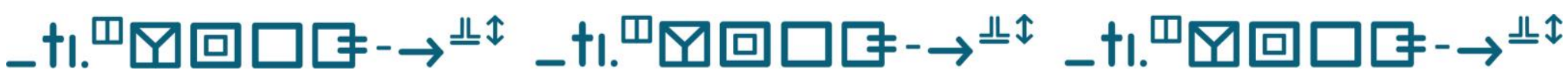

Cotejo entre dois dicionários de Libras: análise de microparadigmas Leandro Andrade Fernandes • Vanessa Regina Duarte Xavier

FERNANDES, Leandro Andrade; XAVIER, Vanessa Regina Xavier: Dicionários de Libras: proposta basilar de um roteiro lexicográfico e/ou terminográfico. Revista The Especialist. v. 40, n. 3, p. 2318-715, 2019. Disponível em: https://revistas.pucsp.br/index.php/esp/article/view/42495/30739. Acesso em: 12 dez. 2020.

GAMA, Flausino José da Costa. Iconografhia dos signaes dos surdos-mudos. Rio de Janeiro: Tipographia Universal de E. \& S. Laemmert, 1875.

GONÇALVES, Sheila de Carvalho Pereira. Estudo de dicionários escolares e proposta de elaboração de dicionário infantil de língua portuguesa. 380 f. Tese (Doutorado em Estudos Linguísticos) Universidade Estadual Paulista UNESP: São José do Rio Preto, 2013. Disponível em: https://repositorio.unesp.br/handle/11449/100093. Acesso em 13 nov. 2021. HONORA, Márcia; FRIZANCO, Mary Lopes Esteves. Livro ilustrado de Língua Brasileira de Sinais: desvendando a comunicação surda. São Paulo: Ciranda, 2009.

HONORA, Márcia; FRIZANCO, Mary Lopes Esteves. Livro ilustrado de Língua Brasileira de Sinais: desvendando a comunicação surda. São Paulo: Ciranda, 2010.

HONORA, Márcia; FRIZANCO, Mary Lopes Esteves. Livro ilustrado de Língua Brasileira de Sinais: desvendando a comunicação surda. São Paulo: Ciranda, 2011.

KRIEGER, Maria da Graça; Rangel, Egon de Oliveira. Questões políticas. In. XATARA, Claudia et al. Dicionário na teoria e na prática: como e para quem são feitos. São Paulo: Parábola Editorial, 2011.

MURAKAWA, Clotilde de Almeida Azevedo; ZAVAGLIA, Claudia. Questões teóricas específicas. In. XATARA, Claudia et al. Dicionário na teoria e na prática: como e para quem são feitos. São Paulo: Parábola Editorial, 2011. 


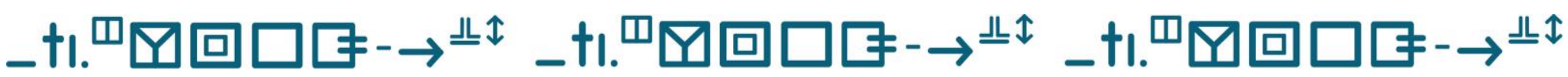

Cotejo entre dois dicionários de Libras: análise de microparadigmas Leandro Andrade Fernandes • Vanessa Regina Duarte Xavier

NASCIMENTO, Cristiane Batista do. Terminografia em língua de sinais brasileira: proposta de glossário ilustrado semibilíngue do meio ambiente, em mídia digital. 222 f. Tese (Doutorado em Linguística) Universidade de Brasília UnB: Brasília, 2016. Disponível em: https://repositorio.unb.br/handle/10482/21851. Acesso em: 13 nov. 2021. OATES, Eugenio. Linguagem das mãos. Rio de Janeiro: Editora Livro, 1969. PÉLISSIER, Pierre. L'enseignement primaire des sourds-muets à la portée de tout le monde aec iconographie des signes. In: Aux origines de la langue signaes Françoise: Brouland, Pélissier, Lambert los premiers illustrateurs. Paris: A la Librarie de Paul Dupont, 1856.

SILVA, Luciana Ferreira Pinto da. Estudo crítico da representação visual do léxico em dicionários infantis ilustrados. 2006. 136 f. Dissertação (Mestrado em Linguística) Universidade de Brasília - UNB: Brasília, 2006. Disponível em https://repositorio.unb.br/handle/10482/8880. Acesso em: 02 out. 2020.

SOFIATO, Cássia Geciauskas. O desafio da representação pictórica da Língua de Sinais Brasileira. 2005. 114 f. 2015. 121 f. Dissertação (Mestrado em Artes) Universidade Estadual de Campinas - UNICAMP: Campinas, 2005. Disponível em: http://repositorio.unicamp.br/handle/REPOSIP/285074. Acesso em: 28 jun. 2020.

REY-DEBOVE, Josette. Étude linguistique et sémiotique des dictionnaires français contemporains. Paris: Hachette, 1971.

STEIN, Gabriele. Illustrations in dictionaries. International Journal of Lexicography. Oxford University Press, v. 4, n. 2, p. 99-127. 1991.

WELKER, Herbert Andreas. Dicionários: uma pequena introdução à lexicografia. Brasília: Thesaurus, 2004.

\section{Publisher}




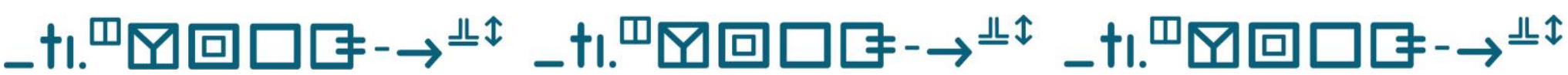

Cotejo entre dois dicionários de Libras: análise de microparadigmas Leandro Andrade Fernandes • Vanessa Regina Duarte Xavier

UNIVERSIDADE FEDERAL DE GOIÁS. CURSOS DE LETRAS: LIBRAS E DE LETRAS: TRADUÇÃO E INTERPRETAÇÃO EM LIBRAS/PORTUGUÊS DA FACUldade de letras/UfG. PublicaçÃo No PORTAL DE PERIÓdicos UFG. AS IDEIAS EXPRESSADAS NESTE ARTIGO SÃO DE RESPONSABILIDADE DE SEUS AUTORES, NÃO REPRESENTANDO, NECESSARIAMENTE, A OPINIÃO DOS EDITORES OU DA UNIVERSIDADE. 